\title{
Review of Fungi Found on the Skin on the Basis of the 1948 Material.
}

From the Department of Serology and Bacteriology, University of Helsinki, Division of Parasitology

Risto Pätiälä and S. Härö.

I.

A Study of Dermatophytes in Finland in 1948

Work done by one of us on dermatophytes (Pätiälä 1945) from 1941 to 1945 gave the following results:

1. This material collected during four years shows that among the diseases produced by dermatophytes, those due to Trichophyton and Epidermophyton are common in Finland.

2. At least the following skin fungi occur in this country, as illustrated by the table below :

Table I.

\begin{tabular}{|c|c|c|c|c|c|c|c|}
\hline \multirow{2}{*}{\multicolumn{3}{|c|}{ Dermatophytes in Finland $1941-1945$}} & \multicolumn{4}{|c|}{$\mathrm{M}$ a $\mathrm{n}$} & \multirow{2}{*}{ Animals } \\
\hline & & & Hair & Beard & Hairless & Total & \\
\hline \multirow{2}{*}{\multicolumn{2}{|c|}{ I. Microsporon }} & & 0 & 0 & 0 & 0 & 0 \\
\hline & & Tr. crateriforme & 0 & 0 & 2 & 2 & 0 \\
\hline \multirow{2}{*}{\multicolumn{2}{|c|}{ Endothrix }} & $\begin{array}{l}\text { Tr. violaceum .......... } \\
\text { Tr. endothrix species }\end{array}$ & 9 & 1 & 1 & 11 & 0 \\
\hline & & ignota ................ & 0 & 0 & 1 & 1 & 0 \\
\hline \multirow{7}{*}{$\begin{array}{l}\text { II.Tricho- } \\
\text { phyton } \\
\text { Ecto- } \\
\text { thrix }\end{array}$} & & Tr. gypseum asteroides.. & 0 & 1 & 4 & 5 & 0 \\
\hline & & Tr. gypseum granulosum & 1 & 0 & 21 & 22 & 25 \\
\hline & $\begin{array}{l}\text { roi- } \\
\text { des }\end{array}$ & Tr. gypseum persicolor. . & 0 & 0 & 0 & 0 & 1 \\
\hline & & species ignotae .... & 0 & 0 & 2 & & 0 \\
\hline & & Tr. rosaceum .... & 1 & 0 & 0 & $\begin{array}{l}2 \\
1\end{array}$ & 0 \\
\hline & Mega- & Tr. equinum ............ & 0 & 0 & 0 & 0 & 15 \\
\hline & & Tr. faviforme discoides & 1 & 0 & 0 & 3 & 0 \\
\hline \multirow{2}{*}{\multicolumn{2}{|c|}{ III. Epidermophyton }} & inguinale... & 0 & 0 & 25 & 25 & 0 \\
\hline & & ${ }^{n} \mid$ interdigitale & 0 & 0 & 19 & 19 & 0 \\
\hline \multicolumn{3}{|c|}{ IV. Achorion } & 0 & 0 & 0 & 0 & 0 \\
\hline & & All & 14 & 2 & 76 & 92 & 41 \\
\hline
\end{tabular}


3. Among the clinical pictures trichophytia predominates to the extent of nearly one-half of the material; next is Eczema marginatum closely followed by epidermophytia of the foot. Deep trichophytia of the beard has only been found in individual cases. There has been only one epidemic of aphlegmatic trichophytia, which is rare in our country.

A considerable number of patients, with tricophytia had undoubtedly contracted their disease from cattle. This was the case with the Trichophyton gypseum granulosum epidemic in the parish of Luopioinen.

Additional studies revealed the following. $P$ ätiälä ${ }^{11}$ ) published a case of trichophytia produced by Trichophyton

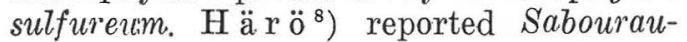
dites gypseum as an asymptomatic fungus finding revealed at mass examinations and published another paper ${ }^{6}$ ) on asymptomatic ringworm of the feet where only Trichophyton gypseum (Trichophyton interdigitalis) was found, apart from the Sabouraudites gypseum already mentioned. $\mathrm{P}$ äti äl ${ }^{12}$ ) reported increased frequency of Tinea pedis in Finland on the basis of a series collected during 6 months in 1947, concerning ringworm of the feet.

The aim of this paper is to supplement the work on dermatophytes in Finland under peacetime conditions, particularly as far as the appearance of symptomatic fungi is concerned, also taking into account some other simultaneously studied cases.

\section{Writers' own investigations.}

The material comprised: a) clinical specimens of the Parasitological Department and b) mass examinations.

The elinical material was chiefly supplied from the southern parts of Finland. The mass examinations were performed at the garnisons of Hyrylä and Riihimäki, where recruits came from all over the country. The series was collected in 1947 -1948, when normal conditions had established themselves in every way, including nutrition. Thus it differs completely from the material of P ätiäl ä's ${ }^{10}$ (1945) fundamental work, provided by the Dermatogical Clinic of the University at Helsinki.

There were 227 dermatological cases and examinations had been performed on men and women.

\section{Methods.}

The technique of taking specimens was the ordinary one in cases of ringworms, and the samples often arrived in tubes accompanied by a correct diagnosis.

The technique is of great significance in cases of onychomycosis. This is particularly the case in the taking of specimens of nail for fresh preparations, which should be done by the method illustrated in Fig. 1. If the specimens are taken in
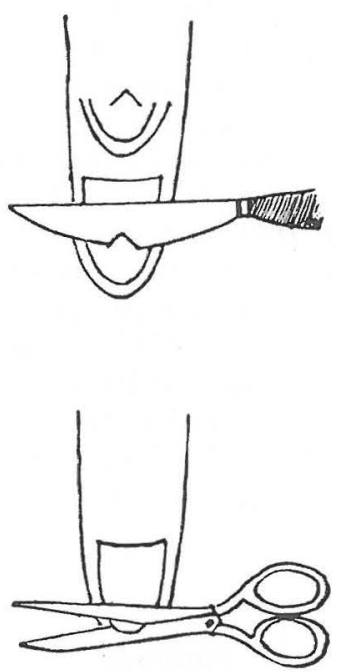

Fig. 1.

Method of taking specimens of fungi from the nails. 1. the right, 2 . the wrong method.

the proper way, the fungal threads running lengthwise to the nail come off whole and are easy to diagnose, whereas they get severed when taken in the wrong way.

In mass examinations we applied a technique suitable to them by taking a specimen from the region between the 4 th and 5 th toe. Native preparations were not made 
at mass examinations. The technique of taking fungus specimens actually has great significance, particularly in the study of asymptomatic cases. Experience has shown that in clinical cases of fungus affecting the feet, where fungi can be demonstrated in microscopic preparations, it is not always possible to cultivate them. On the other hand, the fungus can grow when cultivated on an artificial nutritive substance, although it cannot be demonstrated microscopically. Sylvest, in Denmarkk, ${ }^{13}$ (1948) by cultivating fungi from between the 4th and 5 th toes found them in only 5 per cent, but by combining specimens taken from other parts of the foot with the results of results of microscopic examinations, asymptomatic fungi were found in 19 per cent of cases examined.

In mass examinations the technique employed by Sylvest ${ }^{13}$ ) proved much too inconvenient, particularly when several hundreds of samples had to be taken in succession. We did not have recourse, therefore, to any examinations of fresh microscopic preparations, but only took with a sharp scoop a specimen from between the 4 th and 5 th toe, cultivating it immediately on a 4 per cent maltose agar surface. By that method we were able to avoid factors preventing the growth of the fungi, due to drying or other changes in the conditions. In clinical cases we have determined fungal species both on the basis of microscopic studies of fresh preparations and by cultivation, our chief atten tion being directed to the latter.

\section{Findings.}

In dermatological cases dermatophytic fungi (in studies of fresh preparations on find exactly 47 fungus) grew in 45 specimens. Mass examinations revealed dermatophytic fungi in 54 specimens. In 1948 the following fungi were found in clinical cases: Trichophyton gypseum 41 instances, Trichophyton violaceum 2, Epidermophyton inguinale 1, Achorion gypseum 1 and 1 Achorion Gallinae instance. The latter is the only geographically new class found by us. Fig. 5. It was isolated from the blackeock (Tetrao tetrix).

\section{Studies of findings.}

I. The Microsporon Group. - It proved ved futile to look for fungi of the microsporon group. The absence of this fungal genus in our series may be due chiefly to climatic conditions. It is striking that our cultivated strains as well died twice within a short time.

II. The Trichophyton Group. - (a) The presence of fungi of the Endothrix-group seems to be constant but scarce to numbers. The appearence of Trichophyton violaceum is sporadic and it is, like other fungi of the endothrix group, relatively uncommon.

The case in which Trichophyton violaceum appeared in the finger nail is of interest; the growth had originated in the parish of Salmi (Fig. 2) in the territory ceded to Russia in the east part of the country. In another case, from the vicinity of the town of Lahti, this fungus grew in the hair.

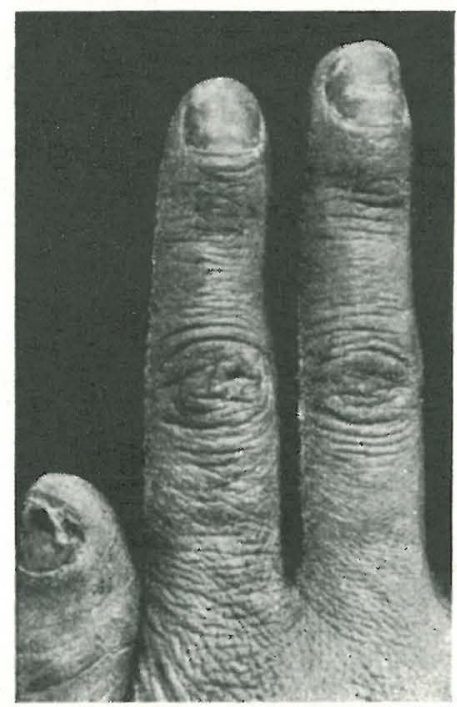

Fig. 2.

Photo of onychomycosis due to Trichophyton violaceum.

b) Ectothrix fungi are represented in the series to a greater extent. Particularly the downy Trichophyton gypseum type occured very often. Since the fungi of this group manifest themselves clinically or appear in mass examinations, it is best to deal separately with each group. 


\section{Clinical manifestations of the trichophyton group.}

1. Clinical diseases of the feet producing subjective symptoms caused by fungi.

In the course of 1948, 48 clinical cases of feet were studied at the Parasitological Department of the University of Helsinki. There was a suspicion of dermatophytes as causative agents. Mass examinations are not taken into account here. Among these cases we found Trichophyton interdigitalis in 40 and in one instance a fungus of the type Trichophyton gypsewm asteroides. When conditions became stabilised after the war the diseases produced by dermatophytes apparently assumed a less severe character, and among those examined only 2 cases revealed what should be considered as extensive clinical changes produced by dermatophytes.

\section{Clinical cases of fungi affecting the hands.}

In the course of the above-mentationed period we examined 13 patients in whom dermatophytes were suspected to be the cause of the disease. The majority of the patients were women - chiefly engaged in housework. In 2 cases there was a growth of Trichophyton interdigitalis of the same class an on the feet. One of the cases was a Helsinki physician who had his fungus on his thumb and first finger. We have not taken into account those cases where the finger or toe nails alone had undergone changes.

\section{Onychomycosis.}

In the clinical cases descibed above of fungi affecting the feet, 22 instances revealed clinical changes in the nails of the toes and 32 instances revealed clinical changes of the finger nails. Of the specimens taken in these cases, 11 revealed the growth and symptoms of dermatophytes. In Pätiälä's series onychomycosis was not found at all. Since the diseases of the nails caused by fungi have hardly become more frequent, the cause is rather to be sought in improved technique (see the paragraph dealing with technique). The chief agent responsible for the appearance of chronic affections produced by fungi was often proved to be a focus concealed in the nail, which persistently spreads over the skin or causes repeatedly phytid formations often resembling Dermatitis lamellosa sicca (Fig. 3). Onychomycosis often

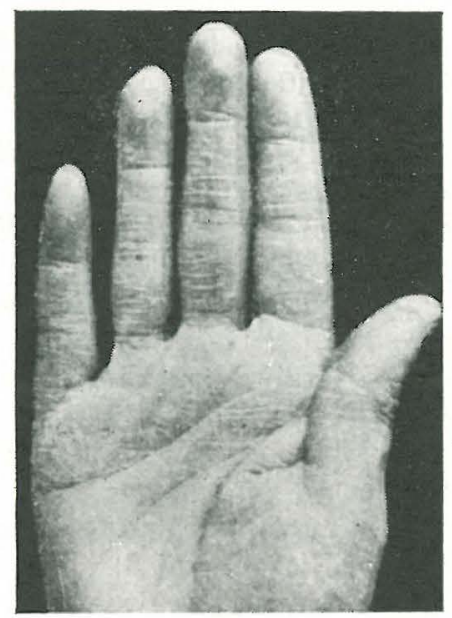

Fig. 3.

Dermatophytia resembling dermatitis lamellosa sicca found in a case of onychomycosis due to Tr. violaceum.

starts in the lateral edge of the nail or in its outer corners. Our series contain a case which is an exeption.

Case 1. A shopkeeper's wife aged 30 years from the parish of Helsinki. She had

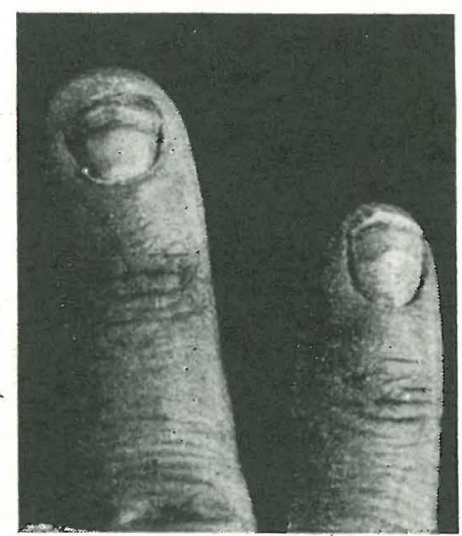

Fig. 4.

Photo of a Trichophyton interdigitalis infection transferred to the little finger through treat. ment of the nail. 
undergone treatment of the nails in the spring of 1948 , subsequent to which there were changes one month later, reproduced in Fig. 4. Fungus diagnosis: Trichophyton interdigitatis. It is noteworthy that the infection spread from the nail-wall and during the treatment.

It is evident that a fungus was covered into the nail-fold by instruments during treatment, afterwards spreading into the nail-bed.

Only Lew is and Hop per (1943) ${ }^{5}$ ) claim to have found a case where the dissease began in the nail-walls.

In 15 cases Trichophyton interdigitalis could be diagnosed and in one case there was a growth of Trichophyton violaceum from the nail. The modifications of the nail brought about by the latter are relatively uncommon. Figs. 3 and 4.

Case 2. - Grain magazine hand from Salmi, aged 23. He had had nail symptoms for a time of 9 years. Dermatitis lamellosa sicca was cleared at once as soon as the nails were removed. Fungus diagnosis: Tr. violaceum. Figs. 2 and 3.

We have classified, below, our clinical cases and fungi isolated from them:

Table II.

Fungi isolated from clinical cases

\begin{tabular}{r|c|c|c|c|}
\hline \hline \multicolumn{1}{c|}{ Fungus } & Foot & Hand & $\begin{array}{c}\text { Toe } \\
\text { nails }\end{array}$ & $\begin{array}{c}\text { Finger } \\
\text { nails }\end{array}$ \\
\hline \begin{tabular}{l|c|c|c|} 
Tr. interdigit. ... \\
Tr. violaceum $\ldots$
\end{tabular} & 14 & 2 & 9 & 6 \\
E. inguinale ... & 1 & - & - & 1 \\
\hline Total & 15 & 2 & 9 & 7 \\
\hline
\end{tabular}

\section{Clinical incidence of fungi.}

On the basis of our own clinical cases we can get a better idea than before of the actual spread of diseases produced by fungi in Finland, although we only had laboratory material at our disposal. A fairly accurate idea of the changes in this respect is supplied by Table III, complied on the basis of the entries at the Outpatients' Department of the Dermatological
Clinic of the University, Helsinki, in groups of three years divided into 3 decades. We have taken as one group all cases probably of fungus origin althout without mycological examination - the ringworm of hands and feet was increased in Finland superficial and deeps fungus diseases appearing in the body remain unchanged.

Dermatoses of probably fungous origin collected from the records of the Dermatological Out-patients' Department of the Dermatological Clinic of the University Helsinki * :

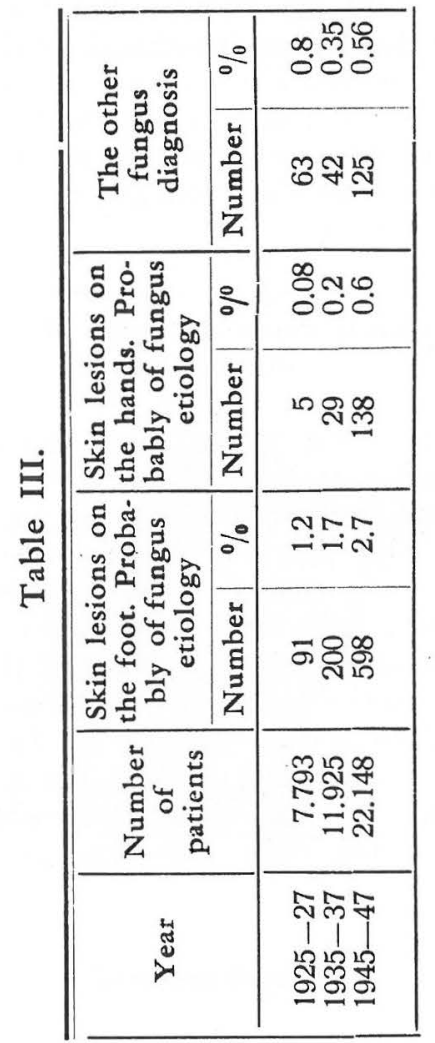

\section{Manifestations of trichophyton group in mass examinations.}

We are dealing with these examinations in this connection, as all dermatophytes ascertained belong to this group, aside from one exception described later.

*) This information was kindly placed at our disposal by Professor P. Pirilä, NI. D., for which we have to thank him. 
Our mass examination material, collected with a view to investigating chiefly in what way military service affects the spread of the fungi, their incidence among the young age groups, frequency and relation to the length of the service time, was taken by us from 1947 apparently healthy individuals. Of them 944 were conscripts, 131 belonged to the regular armed forces, and 172 were women of the same age (student nurses, registered nurses, etc.).

The mass examinations were carried out among the troups at Hyrylä in the winter of 1947-48 and at Riihimäki in the summer 1948; the medical staff was likewise examined in the summer of 1948.

Age. - Our mass examinations series consisted mainly of persons 20 years old and only a few older ones, but, together with earlier investigations (Table IV), it throws light on the distribution of these fungi among the different age groups,

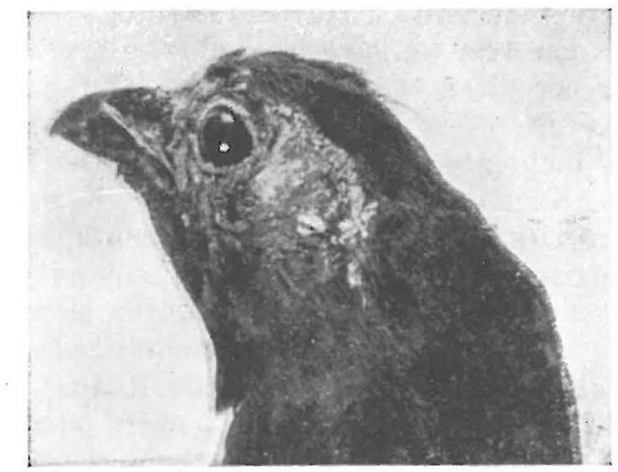

Fig. 5.

Photo of Achorion gallinae infection in blackcok (from Game Research Institute, Helsinki, P. Rautatienk. 13).

while the uniformity of the grouping provides evidence that these fungi were of common occurrence even previously in this country with us. Pätiälä ${ }^{10}$ ) found that in this country fungous diseases with clinical symptoms are most common among individuals 20 to 30 years old. $\mathrm{H} \ddot{\mathrm{ar}} \ddot{o}^{6}$ ) ascertained that the older age groups yielded at least equally frequent asymptomatic findings of fungi as the younger ones. (5.9 per cent).

Sylvest ${ }^{13}$ ) found that asymptomatic fungus of feet is most common in Denmark among those 31 to 40 years old.
Season. - The incidence of fungi is by no means identical during different seasons. Specimens were taken from 429 recruits and 62 persons on the regular staff of the army in the winter of 194748 , and 515 and 69 respectively in the spring of 1948. The conscripts of both groups had been in service for 3 months on an average and the groups were similar also in other respects. In addition, specimens were taken in summer of 1948 from 172 women.

Table IV.

Percentage of Trichophyton interdigitalis on the basis of mass examinations in summer and winter

\begin{tabular}{lrc}
\hline Tr. interdigitalis & Summer & Winter \\
\hline Conscripts & 5.4 & 1.4 \\
Regular forces & 11.6 & 4.8 \\
Women & 5.2 & was not studied \\
\hline
\end{tabular}

According to Table V, Trichophyton interdigitalis is much more common in summer than in winter both among conscripts and the regular armed forces. The same results were obtained in 1929 in the examinations of students in California. ${ }^{10}$ ) The material having been similar in both groups, the results obtained demonstrate fairly accurately the ratio of the fungi in summer and in winter.

Service Time. - Table V shows that the percentage of fungi was considerably higher among the regulars than among conscripts. Since it is to be assumed that the somewhat higher average age of the regulars, i.e., 32.7 years, would in itself be sufficient to produce a higher incidence of fungi, specimens were taken simultaneously (in the summer) from women 20 to 30 years old. The percentage of fungous diseases in the regulars is considerably higher than in these two other groups, which suggests that diseases produced by fungi actually increase if the time of service in the army is long. True, as also shown by the table, women of this age group show much sewer fungous diseases than men. 
Table V.

Relation between the time of service in the army an findings of fungi

\begin{tabular}{lccr}
\hline \hline $\begin{array}{l}\text { Times of ser- } \\
\text { vice in army }\end{array}$ & $\begin{array}{c}\text { Number of } \\
\text { soldiers }\end{array}$ & Fungi & $\%$ \\
\hline 1-2 months & 468 & 11 & 2,4 \\
$5-6$ " & 399 & 22 & 5,5 \\
$8-9 \quad 7$ & 77 & 1 & 1,3 \\
& & & \\
$1-4$ years & 17 & 1 & 5,3 \\
$5-9$ - & 59 & 6 & 10,2 \\
$10-14 \quad$ & 23 & 1 & 4,3 \\
\hline
\end{tabular}

We shall hardly be wrong if we assume that, with a lengthening of the time of service, diseases due to fungi also increase, and that they can be positively regarded as occupational diseases of professional soldiers.

\section{Incidence of fungi in different parts of the country.}

The material obtained from among recruits who had hardly had time to become infected in the army was divided by us into different groups according to the native province.

\section{Table VI.}

Provinces, countryside, towns; Dermatophyte percentages

\begin{tabular}{|c|c|c|c|}
\hline & Examined & Fungi & $\begin{array}{l}\text { Per centage } \\
\text { of those } \\
\text { examined }\end{array}$ \\
\hline Uusimaa & 79 & 3 & 3.8 \\
\hline Turku and Pori & 120 & 10 & 8.3 \\
\hline Häme $\ldots \ldots \ldots \ldots$ & 67 & 3 & 4.5 \\
\hline Kymi $\ldots \ldots \ldots \ldots$ & 55 & 一 & - \\
\hline Mikkeli & 31 & 2 & 6.5 \\
\hline Kuopio .... & 61 & 1 & 1.6 \\
\hline Vaasa ..... & 83 & 8 & 9.6 \\
\hline Oulu and Lappi. & 19 & 1 & 一 \\
\hline Town population & 149 & 12 & 8.1 \\
\hline Country " & 366 & 16 & 4.4 \\
\hline
\end{tabular}

Those belonging to the town population exhibited a percentage of 8.1 , the corresponding figures for the country population being 4.4 percent, i.e. unmistakably less. There was also a very marked differ- ence in the fungus percentage of different provinces. Fungus appears to be most common in South Ostrobothnia, next in the province of Turku and Pori, i.e., in the western districts of our country.

\section{Ways of contamination.}

It is possible that the disease spreads in the army by means of boots, which often get exhanged after repair, therefore specimens of fungi were taken from 30 pairs of boots. They revealed a profuse growth of saprophytes (Alternaria) but no dermatophytes.

Specimens (15) were also taken from the men's baths and lavatories. Particularly saprophytes grew in abundance, but no dermatophytes. In one instance there was a growth of Monilia.

Our investigations do not allow of any conclusions as to the ways the infection is carried. In spite of the industrialisation of our country, we have been able to preserve our hereditary tradition of the sauna, and have therefore avoided the great rise in the incidence of the ringworm of the feet attendant on the industrialisation in other countries. Yet a higher percentage of fungus is already noticeable among the town population in our country as well. Our bathing system characterized by small family saunas, (steam baths) as well as the disinfecting power of this bath, ${ }^{4}$ have probably had their share in preventing fungous diseases from spreading over larger areas.

Dermatophytes and diseases produced by them are generally to be found in places where bathing and washing is practised by several persons using the same bath or sink, as customary in England and particularly in America ${ }^{1}$.

We maintain that bathing places and exchange of footwear are of a decisive significance in the spread of disease.

\section{Clinical symptoms manifested in mass examinations.}

Although the majority of those examined were asymptomatic, yet we found symptoms and signs in 15 examined cases in 
winter and in the summer in 22 conscripts and 13 regulars. Of the clinically determined suspect cases among the men, Trichophyton interdigitalis grew in summer in 6 instances among the suspect ones contribbuted by the regulars. It must be taken into consideration that the cases had undergone treatment before the taking of samples.

While examining the feet, we felt thoroughly convinced that it is very difficult to diagnose a fungous disease even on the basis of prominent clinical symptoms and signs - particularly where the feet are concerned. Changes brought about by intertriginous fungus diseases greatly resemble chafes between the toes affecting many people, especially if they walk much and do not wash their feet sufficiently often. This could be observed most clearly while examining soldiers. Therefore we only regarded such changes as clinical symptoms, where desquamation of the skin between the toes was clearly seen, with thin granulation tissus between the scaly strips or blood effusion on the surface. Such skin was unusually in sharp contrast to the surrounding skin. The matter becomes perfectly clear if the affected region also exhibits vesicles containing transparent fluid. Similar changes were also seen under the metatarsus, particularly on the median margin as well as on the median side of the foot. Among subjective symptoms, a severe itching was the one most pronounced. The symptoms described above are common in cases produced by Trichophyton interdigitalis, but changes resembling those brought about by ringworm could be seen on healthy feet as well after prolonged marching, and the mycological examinations prevealed saprophytes or nothing at all.

$\mathrm{Här} \ddot{o}^{7}$, on the other hand, has a comparatively smaller number of young age groups. In practice, the ringworm of the feet is significant, above all in the younger age groups, for large numbers of men belonging to these groups (conscripts) come to live together in circumstances where foot hygiene is inadequate; it is worthy of note that several workers are of the opinion that the present high incidence of fungi is due to infection communicated by the army in wartime ${ }^{1}$. Pätiälä ${ }^{12}$ found as well in his clinical material that fungus in our country may be generally after the average found to any greather extent in this group than in the others, where $\mathrm{Hä} r \ddot{o}^{6}$ demonstrated fungi on average in 5.9 cent.

III. The Achorion Group. - Achorion of the Schönlein type was not found, which may be partly due to the sauna, a typically Finnish bathing custom. An asymptomatic Achorion gypseum was found in toes and a countryman from the Nakkila parish had the same fungus producing symptoms; he said he had got the infection from handling cows, but this was not checked up. Achorion Gallinae was found in blackcock (fig. 5).

$I V$. The Epidermophyton Group. There was only an case of the Epidermophyton group. Who was localised in the inguinal fold, clinically. a case of Epidermophyton inguinatis.

\section{Summary.}

1. In 1948, Trichophyton gypseum interdigitalis was the most common fungus in Finland, occuring both with and without clinical symptoms. During that year there were only a few isolated cases of Trichophyton violaceum, Achorion gypseum, Achorion gallinae, and Epidermophyton inguinale. Epidemics were infrequent.

2. The number of fungi in the nails was abundant. Inseveral cases the nail seemed to maintain the infection over the winter, until a more propitious season of growth.

3. The ringworm disease appears to be an occupational disease among the armed forces, particularly the regulars.

4. While Trichophyton interdigitalis encountered in 3.4 per cent of asymptomatic cases, in 84 per cent of cases with clinical symptoms and signs, and in 20 per cent of cases where mass examinations revealed symptoms. The investigation showed that Trichophyton interdigitalis has to be regarded as a pathogenic fungus. 


\section{II.}

\section{Fungi Found on the Skin Not Included in Dermatophytes Proper.}

In connection, with studies concerning the occurrence of dermatophytes in Finland a large number of other fungi were encountered. The majority of them have to be regarded as mere saprophytes, while some had a pathogenic titre (Candida).

The part played by the fungi cultivated from various kinds of superficial dermatosis in the clinical pictures of these conditions is usually difficult to assess. Several authorities think that even dermatophytes proper cannot cause dermatosis alone, without other coincident factors. On the other hand, there is evidence of pathological conditions caused by saprophytic fungi. In the present article, the occurrence of various species of fungi is discussed without paying attention to their role in the rise of pathological conditions.

The material and technique were the same as those used in that part of our work which dealt with dermatophytes.

\section{Species of fungi observed.}

The fungi isolated from the clinical material and discovered at mass examinations were classified according to species into main groups. Table 1 shows the number and percentage of fungi in these groups. Each group will be dealt with briefly and some relevant cases reported.

\section{Yeast-like fungi.}

In 1948 we isolated fungi of this type in 39 of aur clinical cases. They were distributed as follows:

The group Candida: C. guillermondi 1

C. albicans 2

C. tropicalis 3

C. krusei 4

Not diagnosed (Torula etc.)

29

This group includes fungi with an obviously pathogenic titre and therefore some cases are reported.

\section{Table I.}

Species of fungi (number and percentage) isolated from clinical and mass examination material.

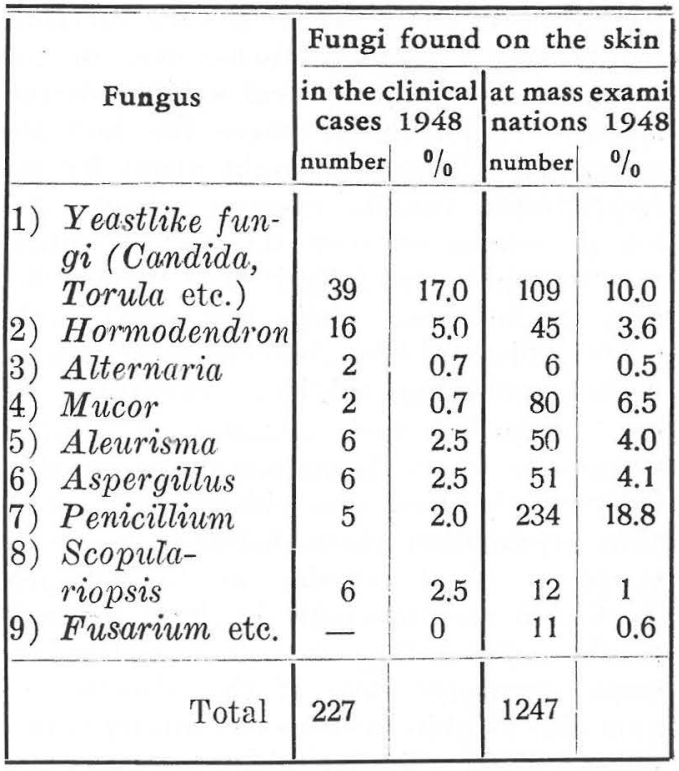

\section{Clinical Cases}

(a) "Deep" clinical cases due to yeastlike fungi.

These cases numbered two. Both were chronic; one was due to C. albicans, the other to $C$. tropicalis. In the latter the diagnosis was confirmed by Dr. Norman F. Conant, Durham University, U.S.A. Four cases of blastomycosis due to $C$. albicans have previously been diagnosed in Finland. $\left.{ }^{12}\right)$ -

(b) Diseases with symptoms in the legs.

In 12 cases we isolated a yeast-like fungus from foot dermatoses (nails). Of these one was due to $C$. albicans and 4 to $C$. krusei and C. tropicalis, 7 to unspecified yeast-like fungi (not definitely distinguished.) It was typical of the clinical cases in which yeast-like fungi were pres- 
ent that the interdigital areas were covered by white fairly firm macerated skin and only on the border of the healthy and the pathological skin was there a slightly red thin-skinned a $x$ ea. Usually there were no changes in the plantar region. These cases were characterized by very marked perspiration of the feet. The cases were superficial and did not clinically differ so much from the conditions produced by dermatophytes proper that definite diagnosis would have been possible without culture. Often a yest-like fungus must be regarded only as an incidental finding.

\section{(c) Diseases with symptoms in the hands.}

The patients were mostly women doing housework. Changes due to yeast-like fungi were generally found in the hands and feet, especially the nails.

In one case culture yielded $C$. albicans, in 2 cases C. tropicalis, and in one case C. guillermondi. The remaining cases were due to saprophytes of the group Toruta (4). In 2 cases infection of the nail wall with typical swelling was noted.

In 2 cases dermatophytes and yeast-like fungi grew from one and the same patient. It seems that the latter are often secondary invaders which prepare the ground for other fungi and bacteria (thick nails). From the nails they spread again to the skin or cause recurring allergic phenomena.

\section{(d) Mass examinations}

In 109 cases culture yielded fungi mostly resembling the yeast-like type. In our material of soldiers the cases were classified according to the season of the year, according to the presence of $\mathrm{symptoms}$ and $\mathrm{sig} \mathrm{ns}$, and according to the duration of service (Table 2).

On the basis of the table nothing can be said as to the pathogenicity. The incidence of fungi was slightly higher in winter, i.e. 6.9 per cent; in summer it was 4.0 per cent. On the other hand, fungi were equally common in those whose who had symptoms and signs and in those who were asymptomatic (6 per cent and 5.6 per cent). Fungi were slightly more frequent in those who had served only a short time than in those whose service was of longer duration.

\section{Hormodendron.}

This fungus occurs also in Finland as a causative agent of allergy. We found in one case that Hormodendron growing in wallpaper caused allergic phenomena in an otherwise healthy individual. Our clinical material included no definitive case of mycosis, though this is considered one of the most important fungi playing a part in many dermatoses. Hormodendron was diagnosed in 16 cases : in 7 in the nails, in 5 in the feet, and in 4 on the skin. In 5 cases the nail samples showed mycelia of the size

Table 2.

Yeast-like fungi found when examining the feet of soldiers, classified according to season, duration of service, and possible symptoms and signs.

\begin{tabular}{|l|r|r|r|r|r|r|}
\hline \hline Season; Duration of service & $\begin{array}{c}\text { Number of } \\
\text { men }\end{array}$ & Fungi found & $\begin{array}{c}\text { Healthy } \\
\text { subjects }\end{array}$ & $\begin{array}{c}\text { Fungi in } \\
\text { healthy } \\
\text { subjects }\end{array}$ & $\begin{array}{c}\text { Symptoms } \\
\text { and signs }\end{array}$ & $\begin{array}{c}\text { Fungi in cases } \\
\text { with symp } \\
\text { toms and } \\
\text { signs }\end{array}$ \\
\hline Summer 2 to 6 months & 487 & 22 & 466 & 21 & 21 & 1 \\
Winter 2 to 6 ,, & 380 & 29 & 370 & 29 & 10 & - \\
Summer 6 to 12 ,, & 28 & 2 & 27 & 2 & 1 & - \\
Winter 6 to 12 & 49 & 3 & 44 & 3 & 5 & - \\
Summer 1 year and more & 69 & 3 & 56 & 1 & 13 & - \\
Winter 1 ,", & 62 & 1 & 62 & 1 & - & - \\
\hline Total & 1075 & 60 & 1025 & 57 & 50 & 3 \\
\hline Total in summer & 584 & 27 & 555 & 24 & 29 & 3 \\
Total in winter & 491 & 33 & 470 & 33 & 21 & - \\
\hline
\end{tabular}


of bacteria, and once culture yielded $T r$. interdigitalis in addition to Hormodendron. Iin our material of soldiers the fungus was considerably commoner in winter, but in samples from women it also grew copiously in summer.

\section{Alternaria.}

This species was cultured in one case reported below; apparently the changes are due to Alternaria whether on an allergic basis or not.

Case 1. A university student, 28 years. The patient had had eruptions on his toes during many summers. In the spring of 1946 there were typical dyshidrotic changes in both feet between the 3rd, 4th and 5th toes. A few itching vesicles appeared on the medial aspect of the right foot and itching vesicles resembling epidermophytids on both hands. Culture yielded Alternaria. Painting with iodine rapidly relieved the symptoms. In July 1947 there were again slight changes between the 4th and 5th toes. About the same time the patient contracted tonsillitis and was given 300.000 units of Ca-penicillin in oil emulsion. The result was that within 3 to 4 hours distinct reddening and swelling and intense itching appeared in all fingers and in the feet, where it began about the middle of the foot and extended distally. Within 3 days the itching vanished and there appeared small vesicles in these areas and to some extent also in the palmar and plantar regions. The vesicles dried and later the covering epidermis loosened and scaled off completely. Alternaria grew in the culture. In 1948 there were slight symptoms and Alternaria was again obtained.

This species of fungus was fairly rare in our material. It appeared in winter and summer and bore no relationship to the clinical pictures seen at mass examinations. It is one of the most important causative factors in allergy.

\section{Mucor.}

In the clinical series this fungus occurred twice, but not so convincingly that it could be considered responsible for dermatitis though there were long mycelia without transverse walls in the native preparations. At the mass examinations Mucor was found in a total of 80 cases, but there seems to be no correlation between it and the incidence of, symptoms. (Table 4)

This fungus was thus very much commoner in the winter. There are few statements on mucor mycosis in the literature. It probably causes paronychia and occasionally otomycosis and also changes elsewhere on the skin. ${ }^{5}$ )

\section{Aleurisma.}

Among the clinical cases observed in 1948 this fungus was noted in 6 in addition to some other fungus. At the mass examinations no changes in the feet were observed in connection with this species; in the soldiens it occurred only in winter.

\section{6, 7. Aspergillus-Penicillium.}

One strain of $A$. niger was isolated alone from a case of otomycosis and from one case in which the nails were affeeted.

Penicillium often occurred together with some dermatophyte. In the mass examination material fungi were much more fre-

Table 4.

Incidence of mucor in mass examination material

\begin{tabular}{|l|r|r|r|r|r|r|}
\hline \multicolumn{1}{|c|}{ Season } & $\begin{array}{c}\text { Number } \\
\text { of men }\end{array}$ & $\begin{array}{c}\text { Fungi } \\
\text { found }\end{array}$ & $\begin{array}{c}\text { Healthy } \\
\text { subjects }\end{array}$ & $\begin{array}{c}\text { Fungi in } \\
\text { healthy } \\
\text { subjects }\end{array}$ & $\begin{array}{c}\text { Symptoms } \\
\text { and signs }\end{array}$ & $\begin{array}{c}\text { Fungi in cases } \\
\text { with symptoms } \\
\text { and signs }\end{array}$ \\
\hline Winter & 584 & 3 & 555 & 2 & 29 & 1 \\
Summer & 491 & 77 & 470 & 74 & 21 & 3 \\
\hline Total & 1075 & 80 & 1025 & 76 & 50 & 4 \\
\hline
\end{tabular}


quent in winter. In the female they were abundant also in summer.

\section{Scophulariopsis.}

This fungus is also more abundant in the winter. At our mass examinations we were unable to establish any correlation between it and the clinical picture.

The clinical cases in which this saprophyte appeared did not serve to throw light on the disease.

\section{Fusarium.}

This group also includes those cases, noted at the mass examinations, in which pleomorphism made definite diagnosis impossible. Because of the small number of cases no conclusions can be made. In the clinical series this fungus did not occur.

Trichomycosis. Two cases were observed; one of them was from Finland and in it a yellow coccus grew from the skin though the case was clinically red. The second case of infection came from the United States; the clinical picture was brown.

\section{Factors intluencing the fungus tlora.}

In connection with the mass examinations of soldiens in the winter of 1947 we also took samples (15) from the bathhouse (sauna) used by them. It appeared that the same species of fungi were usually abundant in the bath-house, even in its hottest, upper part, from where yeast-like fungi and strains of Hormodendron were cultured. In the lower parts of the bath house and in the dressing room Mucor and Aspergillus were found in large quantities; strains of Penicillium were less frequent.

It is true that the elinical cases and the mass examination material are not fully comparable. However, the high incidence of yeast-like fungi in the clinical cases and of Penicillium and Mucor at the mass examinations deserves notice.

\section{Summary.}

Different fungi were found on the skin as shown in Table 1.

The yeast-like fungi had a highly pathogenic titre, as would be expected. There was a definite correlation between the clinical picture and the incidence of fungi. We occasionally observed even deep clinical changes due to $C$. albicans and $C$. tropicalis. At the mass examinations fungi of this group were very often noted in the absence of any clinical manifestations. Other fungi only rarely cause such manifestations alone (1 case of Alternaria and 2 of $T$ richomycosis) butt hey may be contributory factors. For instance in the cases yielding a dermatophyte proper, Penicit lium, Aspergillus or Mucor was remarkably often demonstrated in addition. It is evident that fungi are important factors producing allengy (our cases of Hormodendron), though this side of the question has not been dealt with here.

\section{References:}

1. Becker, E. L. and Obermayer, M. E.: Modern Dermatology and Syphilology, London 1947.

2. Duncan, J. T.: Brit. Med. J. 1945, 24, 715.

3. " Monthly Bulletin of the Ministry of Health. April 1945. 5.

4. Hirvisalo, K. F.: Acta Soc. Medic. Fenn. Duodecim (Fld), Ser. A. Tom XVI Fasc. 3. 1933.

5. Lewis, S. W. and Hopper, G. M.: An Introduction to Medical Mycology, Chicago 1948.

6. Härö, S.: On the Asymptomatic Ringworm of the Feet in Finland, Ann. Med. Exp. et Biol. Fenn. 1949, 27, 73.

7. Härö, S.: Un cas de Sabouraudites gypseum en Finlande. Ann. Med. Exp. et Biol. Fenn. 1949, 27, 134.
8. Langeron, M.: Précis de Mycologie. Paris 1945.

9. Legge, R. T., Bonar, S. C., Lee \& Templetow, H. J.: J. A. M. A. 1929, 93, 170.

10. Pätiälä, Risto: Untersuchung über die Dermatophyten und die von ihnen hervorgerufenen Krankheiten in Finland. Helsinki Disp. 1945.

11. Pätiälä, Risto: Ann. Parasitol. hum. et comp. 1946, 21, 336.

12. Pätiälä, Risto: Ann. Parasitol. hum. et comp. 1946, 21, 342.

13. Pätiälä, Risto: Sur Tinea pedis et les matières antihistamines le traitement des dermatophytides. Ann. Med. Exp. et Biol. Fenn. 1949, 27, 146.

14. Sylvest, B.: Undersøgelser over subjektiv symptomfri lodsvamp. København Disp. 1948. 